\title{
Optik fiber dalga kılavuzlarının yapı parametrelerinin incelenmesi
}

\author{
Ali ÇETIN ${ }^{1, *}$, Hamza Yaşar OCAK ${ }^{2}$ \\ ${ }^{1}$ Eskişehir Osmangazi Üniversitesi, Fen Edebiyat Fakültesi, Fizik Bölümü, Eskişehir. \\ ${ }^{2}$ Dumlupınar Üniversitesi, Fen Edebiyat Fakültesi, Fizik Bölümü, Kütahya. \\ Gelis Tarihi (Recived Date): 19.08 .2017 \\ Kabul Tarihi (Accepted Date): 23.11 .2017
}

\begin{abstract}
Özet
Optik fiber dalga kılavuzları silindirik geometriye sahip, ışığın içinde yayıldı̆̆ı fotonik devre elemanlarıdır. En genel şekilde iki kısımdan meydana gelir. İç kısmı yüksek kırılma indisli çekirdek olarak adlandırlan kısımdır. Bunu çevreleyen ikinci kısım daha düşük kırllma indisine sahip olup örtü olarak adlandırllır. Optik fiberin özelliği bazı yapı parametreleriyle tanımlanır. Sayısal açıklık, bu dalga kılavuzunun ışıı toplama kapasitesini belirler. Çekirdek ve örtünün kırllma indisleri, ışı̆̆ın dalga kllavuzu içinde ilerleyebilmesi için toplam iç yansımayı sağlar. Normalize olmuş frekans, dalga kılavuzunda yayılan modları belirler. Çekirdek ve örtü kırılma indisleri arasındaki farkı gösteren bağıl kırılma indis farkl, ışığı bu dalga kılavuzunun nasıl kılavuzlandıracă̆ını belirler. Bu çalışmada yukarıda bahsedilen yapı parametreleri arasındaki ilişsiler incelenmişstir.
\end{abstract}

Anahtar kelimeler: Optik fiber, saylsal açıklık, kırılma indisi, dağılım.

\section{Investigation of structural parameters of optical fiber waveguides}

\begin{abstract}
Optical fiber waveguides with cylindrical geometry are photonic circuit elements that light is guided inside. It usually consists of two parts. The inside part which is called as core has high refractive index. The second part that is surrounding the core has lower refractive index and that is called as cladding. The property of optical fiber is defined by some structure parameters. The numerical aperture determines the light-gathering capacity of this waveguide. Refractive indexes of the core and the cladding provide total internal reflection in order to propagating the light inside waveguide. Normalized frequency determines the modes that propagated in waveguide. The relative refractive index difference which indicates the difference between the core refractive index and the cladding refractive index determine how guiding the light in this waveguide. In this study, the relations between the parameters that are given above were investigated.
\end{abstract}

Keywords: Optical fiber, numerical aperture, refractive index, dispersion.

\footnotetext{
*Ali ÇETiN, acetin@ogu.edu.tr, http://orcid.org/0000-0003-0468-8087

Hamza Yaşar OCAK, hyasar.ocak@dpu.edu.tr, http://orcid.org/0000-0003-3094-3459
} 


\section{Giriş}

İletişim, bilginin bir yerden başka bir yere taşınması şeklinde tanımlanabilir. Bilginin ışık ile taşınma düşüncesinin kökeni çok uzun yıllar öncesine dayanmaktadır. İbnü'l Heysem'in çalışmalarında da en çok görme, 1 şı̆̆ın kaynağı, yansıma ve kırılma olayları ele alınmıştır [1]. 1841'de Daniel Colladon ışı̆̆ın su içinde kılavuzlanabileceğini yani yönlendirilebileceğini göstermiştir [2]. Aynı işlemleri 1854'de John Tyndall, Colladon'un yaptığından habersiz olarak gerçekleştirmiştir [3-5]. $\mathrm{Bu}$ çalışmalar karanlık ortamda yapıldığından açık havada su ile hava arasında 1şıma olayı söz konusudur.

Maxwell denklemlerinin 1864 yılında ortaya çıkışından bu yana elektromanyetik dalgaların yayınımı analiz edilmektedir. Maxwell tarafından kurulan matematiksel teoriyle, 1şı̆̆ın elektromanyetik dalga olduğu ortaya çıkmıştır. Bu denklemler elektromanyetik dalga yayınımı ve 1şığın doğasının işleyişi hakkında önemli fikirler vermektedir [6].

1880'de A. G. Bell, fotofon adı verilen aygıtı tasarlayarak ilk kez çalıştırmıştır [7]. Bu aygıtı kullanarak bir 1şın demeti üzerinde ses sinyallerinin iletilebileceğini göstermiştir. Bell tarafından yapılan ışık ile bilgi taşınmasını içeren bu ilk çalışma, açık havada 200 metrelik mesafede güneş ışınını modüle ederek ses iletimini sağlamıştır. Ancak, kapalı havalarda ses sinyallerini iletim verimininin çok düşük oluşu, güneş ışınının boşlukta saçılması, aynı zamanlarda telefonun bulunması, fotofon üzerine yapılan çalışmaların durmasına neden olmuştur.

1910'da Hondros ve Debye 1şı̆̆ın dielektrik ortamda iletimini teorik olarak incelemiştir, ilk örtüsüz cam fiber 1920'de Schriever tarafından elde edilmiştir [5]. 1930 y1lında İngiliz J. L. Baird ile Amerikalı L. W. Hansell kaplamasız fiber kablolar aracılığı ile televizyon görüntülerini tarayarak ve ileterek patent aldılar [8]. Birkaç yıl sonra Alman H. Lamm tek bir cam fiberden görüntüleri başarılı bir şekilde iletti. 1951 yilında A. C. S. Van Heel ile İngiltere'den H. H. Hopkins ve N. S. Kapany fiber demetleri aracılığıyla ışık iletimi üzerine deneyler yaptılar. $\mathrm{Bu}$ bilim adamlarının araştırmaları, tıp alanında tanı ve tedavide geniş bir kullanıma sahip olan esnek fiberskopun geliştirilmesine olanak sağladı [9]. N. S. Kapany, "Optik Fiber" kavramını literatüre kazandırmıştır [10].

Kullanılan 1şık kaynaklarından gelen 1şı̆̆ın dağılması ve 1şı̆̆ı yönlendirecek ortamın uygun olmaması bu konu üzerine çalışmalarda en önemli iki sorun olarak görülmekteydi.
Theodore Maimann 1960 yılının Mayıs ayında ilk katı hal laserini (Yakut laseri) çalıştırmayı başardı. Aynı yıl Aralık ayında Ali Javan ilk kez HeliumNeon laserini keşfetti [11].

Laserin bulunması optik fiber ile ilgili çalışmaları hızlandırdı. Laser yüksek frekansta ayarlanabilme, yönlülük, tek dalga boylu olması, düşük demet ıraksaması gibi önemli özellikleriyle optik iletişim için iyi bir $1 s ̧ ı k$ kaynağı olmuştur. Işık kaynağ1 sorunu çözüldüğü için çalışmalar 1 şı̆̆ 1 içinde yönlendirecek uygun ortam üzerine yoğunlaşmıştır.

1966'da C. K. Kao, G. A. Hockham ve A. Werts tarafından ilk kez örtülü cam fiberin kullanılabileceği önerilmiştir [12]. Başlangıçta fiber optik iletişism sistemleri $1000 \mathrm{~dB} / \mathrm{km}$ 'lik büyük bir zayıflamaya sahipti. On yıl içinde zayıflamanın 5 $\mathrm{dB} / \mathrm{km}$ 'ye düşürülmesi, bunları diğer iletişim sistemleriyle kıyaslanabilir duruma getirmiştir. Zayıflamanın $0.2 \mathrm{~dB} / \mathrm{km}$ 'ye kadar düşürülmesiyle kuramsal alt sınıra ulaşılmıştır.

Bugüne kadar süregelen üretim teknolojisindeki hızlı gelişmelerle fiber optik kablolar seri olarak üretilebilmekte ve bunları içeren iletişim sistemleri diğer iletişim sistemlerinden daha fazla tercih edilmektedir.

Günümüzde hemen hemen her gün yeni bir kullanma alanı ortaya çıkmakta, birçok araştırmacı optik fiberlerin temel karakteristikleri üzerine çalışmalarını sürdürmektedir [13-16].

Optik fiberin kalitesini yapı parametreleri belirler. $\mathrm{Bu}$ çalışmada, yapı parametrelerinin hangi niceliklere göre değiştiği, nasıl etkilendiği ve birbirleri arasındaki ilişkiler nümerik olarak incelenmiştir. Böylece, optik fiberin yap1 parametreleri optimize edilerek bu tümleşik optik devre elemanlarının daha verimli kullanılması sağlanabilir.

\section{Teori}

Optik fiberler silindirik geometriye sahiptir. Geometrik yapısı Şekil 1'de görülen optik fiberde genel olarak kırılma indisi $\mathrm{n}_{1}$ olan bir madde, kırılma indisi kendisinden daha küçük $\mathrm{n}_{2}$ olan başka bir madde ile çevrelenmiştir.

Optik fiberlerin amacı içinde 1şık taşımak olduğu için tam iç yansıma olayının sağlanması gerekir. Bu yüzden iç kısımdaki maddenin kırılma indisi dış kısımdaki maddenin kırılma indisinden daha büyük olmalıdir. 


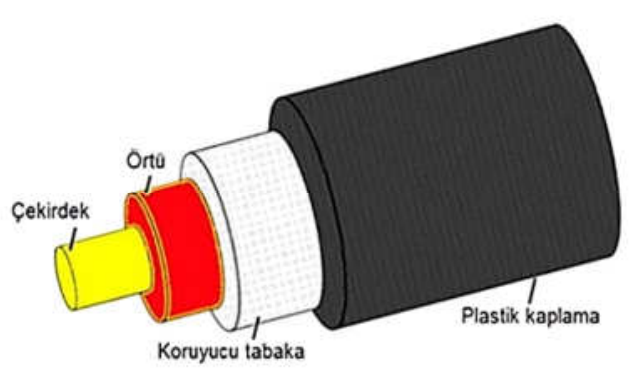

Şekil 1. Optik fiberin geometrik yapısı.

Optik fiberler, kırılma indis profillerine göre basamak indisli ve değişen indisli optik fiber kablolar olmak üzere iki gruba ayrılır. Optik fiber içindeki kırılma indisi bağıntısı

$$
\mathrm{n}(\mathrm{r})=\left\{\begin{array}{c}
\mathrm{n}_{1}\left[1-2 \Delta\left(\frac{\mathrm{r}}{\mathrm{a}}\right)^{\mathrm{g}}\right]^{1 / 2} ; \mathrm{r}<\mathrm{a}(\text { çekirdek) } \\
\mathrm{n}_{2}(1-2 \Delta)^{1 / 2} ; \mathrm{r} \geq \mathrm{a} \text { (örtui) }
\end{array}\right.
$$

ile verilmektedir. Bağıntıdaki a, çekirdek kısmının yarıçapını; $\Delta$ bağıl kırılma indis farkını; g profil parametresini gösterir. $\mathrm{g}$ sonsuz ise optik fiber basamak indisli; g, 1'den başlayarak değer alırsa optik fiber kablo değişen indisli olarak adlandırılır.

Bir ortamdaki elektrik ve manyetik alanların davranışı hakkındaki fiziksel temel, Maxwell denklemleri ile sağlanır. Elektrik alan, manyetik alan, elektrik akı yoğunluğu ve manyetik akı yoğunluğu birbirleriyle

$\mathbf{D}=\varepsilon \mathbf{E}$

ve

$\mathbf{B}=\mu \mathbf{H}$

bağıntılarıyla ilişkilidir. Burada $\varepsilon$ permitivitesi ve $\mu$ permeabilitesi

$\varepsilon=\varepsilon_{0} \varepsilon_{\mathrm{r}}$

ve

$\mu=\mu_{0} \mu_{\mathrm{r}}$

şeklinde tanımlanır. Denklemlerdeki $\varepsilon_{0}$ ve $\mu_{0}$ boşluğun permitivitesi ile permeabilitesi, $\varepsilon_{\mathrm{r}}$ ve $\mu_{\mathrm{r}}$ ise maddenin bağıl permitivitesi ve bağıl permeabilitesidir. Manyetik olmayan maddeler için $\mu_{\mathrm{r}}=1$ alınır. Serbest yüklerin olmadığı $(\rho=0)$, manyetik olmayan maddeler için Maxwell denklemleri aşağıdaki gibidir:

$\nabla \mathbf{X E}=-\frac{\partial \mathbf{B}}{\partial \mathrm{t}}$

$$
\begin{aligned}
& \nabla \mathbf{X H}=\frac{\partial \mathbf{D}}{\partial \mathrm{t}} \\
& \nabla \cdot \mathbf{D}=0 \\
& \nabla \cdot \mathbf{B}=0
\end{aligned}
$$

\section{Modelleme ve simülasyonlar}

Optik fiber, silindirik geometriye sahip olduğundan Şekil 2'deki gibi silindirik koordinatlarda tanımlanabilir.

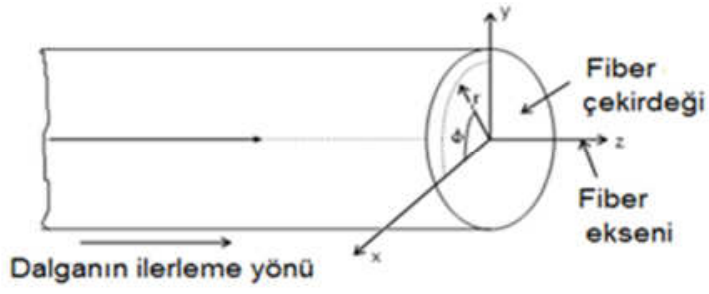

Şekil 2. Optik fiberin silindirik koordinatlarda tanımlanması.

Optik fiber silindirik geometriye sahip olduğundan bunun içindeki elektromanyetik dalganın hareketi Maxwell denklemlerinden yola çıkılarak silindirik koordinatlarda aşağıdaki gibi bulunur [17]:

$$
\begin{aligned}
& \frac{\partial^{2} \mathrm{E}_{\mathrm{z}}}{\partial \mathrm{r}^{2}}+\frac{1}{\mathrm{r}} \frac{\partial \mathrm{E}_{\mathrm{z}}}{\partial \mathrm{r}}+\frac{1}{\mathrm{r}^{2}} \frac{\partial^{2} \mathrm{E}_{\mathrm{z}}}{\partial \phi^{2}}+\mathrm{q}^{2} \mathrm{E}_{\mathrm{z}}=0 \\
& \frac{\partial^{2} \mathrm{H}_{\mathrm{z}}}{\partial \mathrm{r}^{2}}+\frac{1}{\mathrm{r}} \frac{\partial \mathrm{H}_{\mathrm{z}}}{\partial \mathrm{r}}+\frac{1}{\mathrm{r}^{2}} \frac{\partial^{2} \mathrm{H}_{\mathrm{z}}}{\partial \phi^{2}}+\mathrm{q}^{2} \mathrm{H}_{\mathrm{z}}=0
\end{aligned}
$$

Silindirik koordinatlardaki parametreler $(\mathrm{r}, \phi, \mathrm{z})$ olarak verilir. Eșitlik (10) ve (11) sirasıyla elektrik ve manyetik alanların boyuna bileşenlerinin enine değişkenler cinsinden değişimlerini ifade etmektedir.

Bu iki denklem aşağıdaki koșullar altında çözülebilir:

a) $r=0$ için elektromanyetik alan sonlu olmalıdır.

b) $\mathrm{r} \rightarrow \infty$ için $\mathrm{E}_{\mathrm{z}}=0$ ve $\mathrm{H}_{\mathrm{z}}=0$ olmalıdır.

c) $\mathrm{E}_{\mathrm{z}}, \mathrm{H}_{\mathrm{z}}, \mathrm{E}_{\mathrm{r}}, \mathrm{H}_{\mathrm{r}}, \mathrm{E}_{\mathrm{f}}, \mathrm{H}_{\mathrm{f}}$ sınırda sürekli olmalıdır.

i çekirdek ve örtü bölgelerini temsil eden indis olmak üzere

$\mathrm{q}_{\mathrm{i}}^{2}=\omega^{2} \varepsilon_{\mathrm{i}} \mu_{\mathrm{o}}-\beta_{\mathrm{i}}^{2} ; \quad \mathrm{i}=1,2$

alınır.

z'ye dik düzlemdeki değişim için

$\nabla_{\mathrm{t}}^{2}=\nabla^{2}-\frac{\partial^{2}}{\partial \mathrm{z}^{2}}$

eşitliği kullanılarak 


$$
\left(\nabla_{\mathrm{t}}^{2}+\mathrm{q}_{\mathrm{i}}^{2}\right)\left\{\begin{array}{c}
\mathrm{E}_{\mathrm{zi}}(\mathrm{r}, \phi) \\
\mathrm{H}_{\mathrm{zi}}(\mathrm{r}, \phi)
\end{array}\right\}=0 ; \quad \mathrm{i}=1,2
$$

şeklinde iki denklem yazılabilir.

z’ye dik düzlemdeki değişim için silindirik koordinatlardaki dalga denklemini gösteren eşitlikler

$\mathrm{E}_{\mathrm{z}}(\phi, \mathrm{r})=\mathrm{F}(\phi) \mathrm{F}(\mathrm{r})$

$\mathrm{H}_{\mathrm{z}}(\phi, r)=\mathrm{F}(\phi) \mathrm{F}(\mathrm{r})$

şeklinde yazılabilir. Fiber optiğin kesiti dairesel simetrik olduğundan, $v$ pozitif veya negatif bir tamsayı olmak üzere

$\mathrm{F}(\phi)=\mathrm{A} \mathrm{e}^{\mathrm{j} u \phi}$

kabul edilir ve gerekli ara işlemler yapılırsa

$$
\frac{\partial^{2} \mathrm{~F}(\mathrm{r})}{\partial \mathrm{r}^{2}}+\frac{1}{\mathrm{r}} \frac{\partial \mathrm{F}(\mathrm{r})}{\partial \mathrm{r}}+\left(\mathrm{q}^{2}-\frac{v^{2}}{\mathrm{r}^{2}}\right) \mathrm{F}(\mathrm{r})=0
$$

şeklinde Bessel diferansiyel denklemine ulaşılır.

Eş.(1) ile verilen kırılma indisinin yarıçapla değişimi g profil parametresinin sirasiyla 1, 2, 5, 10 ve $\infty$ değerleri için Şekil 3'de çizdirilmiştir.

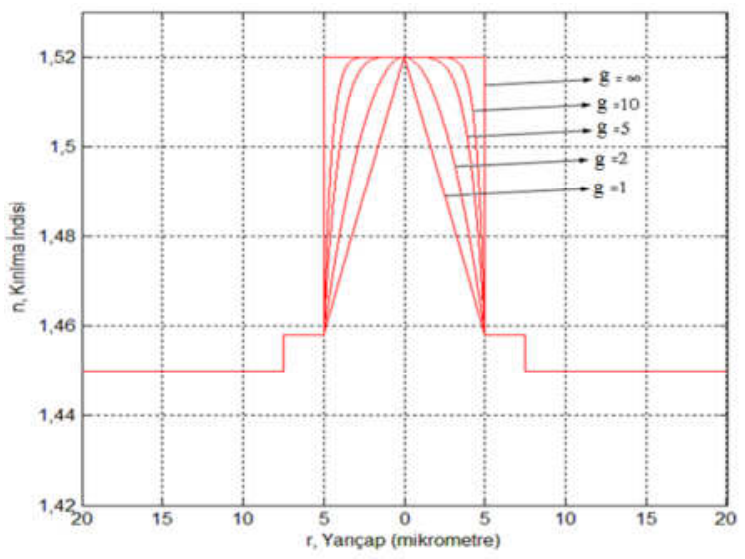

Şekil 3. Optik fiberin kırılma indisinin yarıçapla değişimi.

Şekil 3'den görüldüğü gibi optik fiberin merkezi ekseni üzerinde $r=0$ konumunda çekirdeğin kırılma indisi 1.52 olup çekirdek içinde yarıçap büyüdükçe kırılma indis değeri sabit kalmaktadır. $\mathrm{r}=5 \mu \mathrm{m}$ olunca örtü tabakasına ulaşılıp kırılma indisi 1.4575 oluyorsa optik fiber basamak indisli olarak adlandırılır. $\mathrm{Bu} \quad \mathrm{g}=\infty$ olduğu duruma karşılık gelmektedir. Optik fiberin merkezi ekseni üzerinde $\mathrm{r}=0$ konumunda çekirdeğin kırılma indisi 1.52 olup bu en büyük değerden yarıçap büyüdükçe kırılma indis değeri düşerek $\mathrm{r}=5 \mu \mathrm{m}$ olunca örtü tabakasına ulaşılıp kırılma indisi 1.4575 oluyorsa optik fiber değişen indisli olarak adlandırılır. Bu durumda, $\mathrm{g}=1$ için optik fiber üçgen profile, $\mathrm{g}=2$ için optik fiber kuadratik profile, $\mathrm{g}=\infty$ için optik fiber basamak indis profiline sahiptir.

Eş.(18) ile verilen Bessel diferansiyel denkleminin birbirinden bağımsız iki çözümü vardır. $\mathrm{J}_{v}(\mathrm{ur})$ Bessel fonksiyonu ve $Y_{v}$ (ur) Neumann fonksiyonudur. $\mathrm{r}=0$ 'da elektromanyetik alanın sonlu olması gerektiğinden çekirdek bölgesindeki çözümler, $\mathbf{J}_{v}$ (ur) Bessel fonksiyonları olmalıdır. Koordinat ekseni üzerinde sonsuz değer aldıkları için, $Y_{v}$ (ur) çözümleri kullanılamaz.

Bessel fonksiyonunun kökleri, optik fiber içinde yayılan elektromanyetik modların kesim değerlerini verir. Bu kesim değerlerinden yararlanılarak

$\mathrm{V}=\frac{2 \pi \mathrm{a}}{\lambda}\left(\mathrm{n}_{1}^{2}-\mathrm{n}_{2}^{2}\right)^{1 / 2}$

bağıntısı bulunur. Buna normalize olmuş frekans denir. Bu değer, boyutsuz bir parametre olduğundan optik fiberin $\mathrm{V}$ sayısı ya da $\mathrm{V}$ değeri olarak da adlandırılır. Optik fiber modları, V sayısı sırasıyla, $2.405,3.83,5.14,5.52,6.38,7.02,7.59,8.42 \ldots$ gibi değerler aldığında ortaya çıkar. V sayısı 2.405 değerine ulaşıncaya kadar sadece tek bir mod (EH) mod yayılır. Bu mod, melez enine elekromanyetik moddur. Şekil 4'de optik fiberdeki mod sayısının, V değerine göre değişimi çizilmiştir.

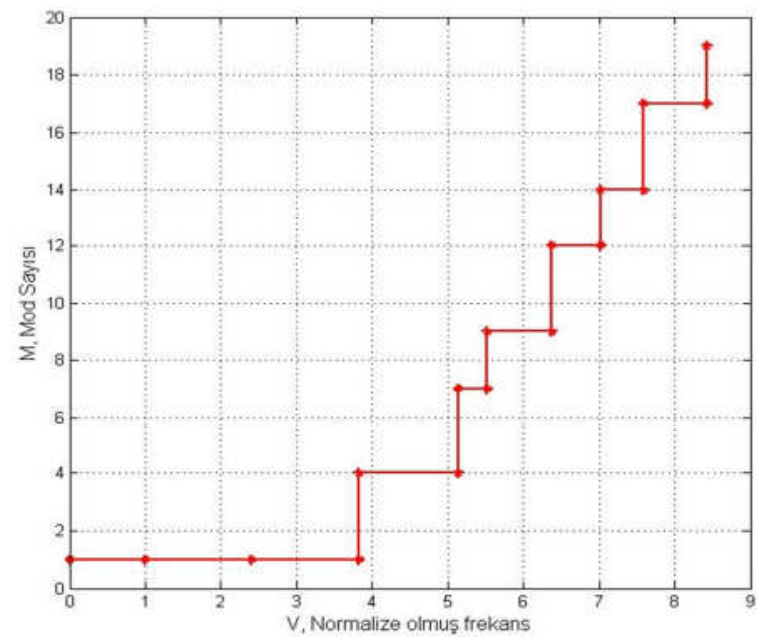

Şekil 4. Mod sayısının, V sayısına karşılık değişimi.

Işığın optik fiber içinde ilerleyebilmesi için, fibere girerken fiber ekseni ile yaptığı en büyük açıya kabul açısı denir ve $\theta_{\text {maks }}$ ile gösterilir. Bu açıya eşit veya daha küçük bir açıda giren 1şık, çekirdek-örtü arayüzeyindeki tam iç yansımalarla, fiber boyunca kılavuzlanır. $\theta_{\text {maks }}$ dan daha büyük açı ile gelen 1 şık ise çekirdek örtü arayüzeyinde tam yansıma koşulunu gerçekleştiremez ve örtü içinde radyasyonla kaybolur. Böylece $\theta_{\text {maks }}$ ile tanımlanan "kabul konisi" içinde kalan 1şın optik fiberin 
çekirdeğinde kalarak kılavuzlanır. Şekil 5'de ilk durumu A 1şını, ikinci durumu ise B 1şını göstermektedir.

Üç ortamın yani çekirdek, örtü ve havanın kırılma indisleri ile kabul açısı arasında bir bağıntı bulmaya çalışalım. Şekil 5'de $\theta_{\text {maks }}$ değerinden daha küçük bir $\theta_{1}$ açısıyla fibere giren 1 şı̆̆ inceleyelim. Snell yasasını D ve E noktalarında kullanarak

$\mathrm{n}_{\mathrm{o}} \sin \theta_{1}=\mathrm{n}_{1} \sin \theta_{2}$

ve

$\mathrm{n}_{1} \sin \phi_{1}=\mathrm{n}_{2} \sin \phi_{2}$

yazabiliriz. DEF üçgenine göre

$\phi_{1}=\frac{\pi}{2}-\theta_{2}$

dir.

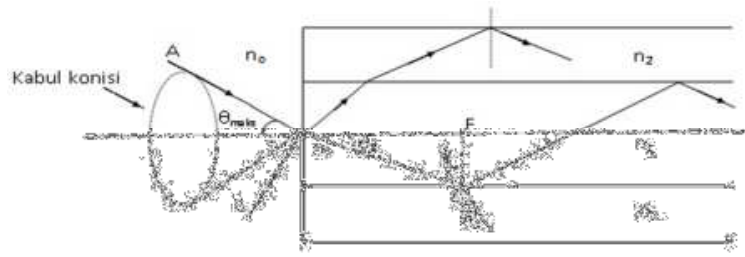

Şekil 5. Bir optik fiberde kabul konisi.

$\theta_{1}$ değeri için üst sınır $\theta_{\text {maks }}$ alınır. E noktasında toplam iç yansımanın sağlanabilmesi için $\phi_{2}$ açısı $\pi / 2$ değerine eşit olmalıdır. Bu sınır değerleri kabul edildiğinde Eş.(20), (21), (22) den yararlanılarak ve $\sin ^{2} \phi_{1}+\cos ^{2} \phi_{1}=1$ trigonometrik özdeşliği kullanılarak

$\mathrm{n}_{\mathrm{o}} \sin \theta_{\text {maks }}=\left(\mathrm{n}_{1}^{2}-\mathrm{n}_{2}^{2}\right)^{1 / 2}$

elde edilir. Boşluğun kırılma indisi $\mathrm{n}_{\mathrm{o}}=1$ kabul edilerek buna 1şığın optik fibere girebileceği maksimum kabul açısı ya da "Sayısal Açıklık" (Numerical Aperture) denilir ve

$\mathrm{NA}=\mathrm{n}_{\mathrm{o}} \sin \theta_{\text {maks }}=\left(\mathrm{n}_{1}^{2}-\mathrm{n}_{2}^{2}\right)^{1 / 2}$

olarak ifade edilir.

Genelde kırılma indislerinin yerine

$\Delta=\frac{\mathrm{n}_{1}^{2}-\mathrm{n}_{2}^{2}}{2 \mathrm{n}_{1}^{2}} \cong \frac{\mathrm{n}_{1}-\mathrm{n}_{2}}{\mathrm{n}_{1}} ; \quad\left(\mathrm{n}_{1} \cong \mathrm{n}_{2}\right)$ şeklinde ifade edilen "bağıl kırılma indis farkı" kullanılır. $\mathrm{Bu}$, optik fiberin önemli yap1 parametrelerinden birisidir. Bağıl kırılma indis fark1 $\Delta$ değeri çok küçük ise optik fibere zayıf kılavuzlayıcı fiber adı verilir [18].

Sayısal açıklık da bağıl kırılma indis farkı cinsinden

$\mathrm{NA} \cong \mathrm{n}_{1}(2 \Delta)^{1 / 2}$

bağıntısıyla ifade edilebilir. Sayısal açıklık, fiberin 1Şı toplayabilme yeteneğinin bir ölçüsüdür. Zayıf kılavuzlayıcı optik fiberde, kırılma indis farkı küçük olacağından sayısal açıklıkta küçük olacaktır. Eş.(24)'e göre sayısal açıklık, optik fibere giren 1şığın fiber ekseni ile yaptığı en büyük açıyı verir [19]. Optik fiberin eksenine göre simetrisinden dolayı $\theta_{\text {maks }}$ açısı fiberin ekseni etrafında bir koni tanımlar. Bu koniye, kabul konisi adı verilir.

Şekil 6'da $\mathrm{n}_{1}=1.52, \mathrm{n}_{2}=1.4575$ olan bir optik fiberde $\mathrm{g}$ profil parametresinin sirasiyla $1,2,5,10$ ve $\infty$ değerleri için sayısal açıklığın yarıçapla değişimi çizdirilmiştir.

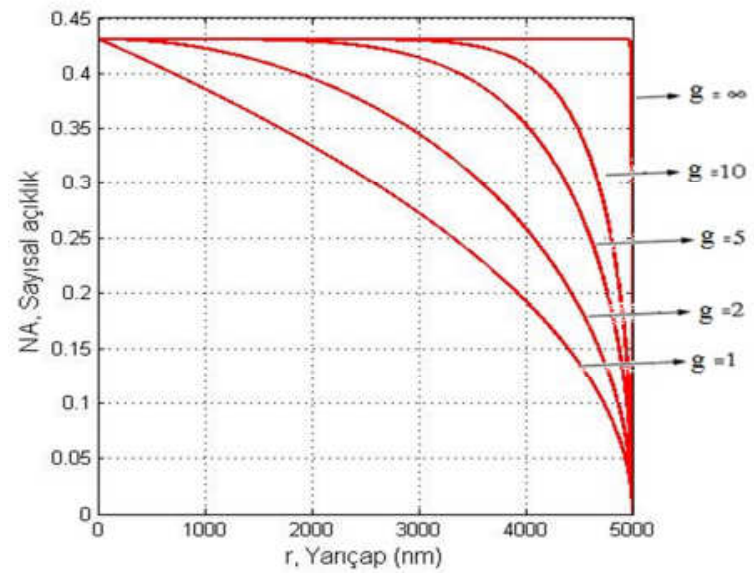

Şekil 6. Bazı g değerleri için sayısal açıklığın yarıçapla değişimi.

Eş.(24)'den görüldüğü gibi sayısal açıklık boyutsuz bir parametre olup sadece optik fiberin çekirdek ve örtü kısımlarının kırılma indisleri $n_{1}$ ve $n_{2}$ değerlerine bağlıdır. Sayısal açıklık değeri Şekil 6'dan görüldüğü gibi optik fiberin ekseni üzerinde çekirdeğin en büyük kırılma indis değeri 1.52 için 0.4313 iken fiber ekseninden dışarıya doğru yarıçap doğrultusunda gidilirse tüm profil parametreleri için sıfır değerine düşmektedir.

Așağıdaki şekillerde Bağıl kırılma indis farkı $\Delta$ 'nın r yarıçapına göre değişimi farklı parametreler için verilmektedir. Şekil 7'de tek mod durumunda yani frekans parametresi $\mathrm{V}=2.405$ alınmıştır. Dalga boyunun $\lambda=632,8 \mathrm{~nm}, \lambda=694 \mathrm{~nm} \lambda=810 \mathrm{~nm}$, $\lambda=1310 \mathrm{~nm}$ ve $\lambda=1550 \mathrm{~nm}$ değerleri için Bağıl 
kırılma indis farkı $\Delta$ 'nın r yarıçapına göre değişimi çizdirilmiştir.

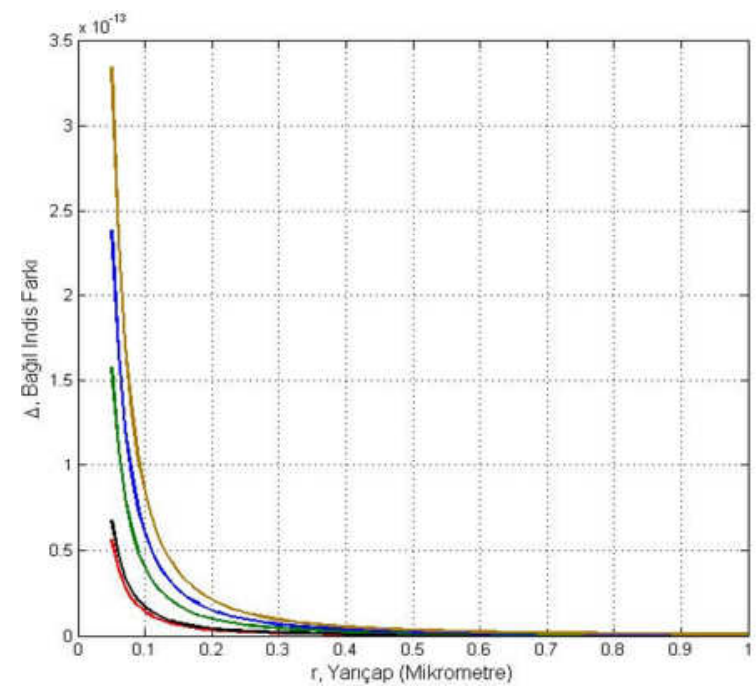

Şekil 7. Bağıl kırılma indis farkı $\Delta$ 'nın farklı dalga boyları için $r$ yarıçapına göre değişimi.

Şekil 8'de tek dalga boyu durumu ele alınmıştır. Dalga boyunun $\lambda=632,8 \mathrm{~nm}$ olduğu durumda $\mathrm{V}=2.405, \mathrm{~V}=2.831, \mathrm{~V}=5.135, \mathrm{~V}=6,380, \mathrm{~V}=7.588$ değerleri için Bağıl kırılma indis farkı $\Delta$ 'nın $\mathrm{r}$ yarıçapına göre değişimi çizdirilmiştir.

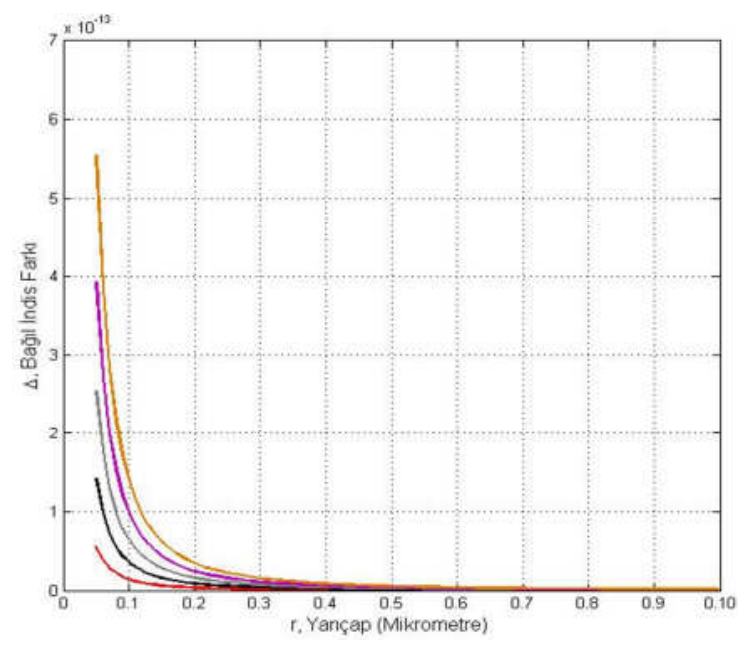

Şekil 8. Bağıl kırılma indis farkı $\Delta$ 'nın farklı V değerleri için $r$ yarıçapına göre değişimi.

Şekil 9'da tek mod durumu ele alınmıştır. Yani $\mathrm{V}=2.405$ alınmıștır. Dalga boyunun $\lambda=632,8 \mathrm{~nm}$ olduğu durumda $\mathrm{n}_{1}=1.42, \quad \mathrm{n}_{2}=1.458, \quad \mathrm{n}_{3}=1.52$, $\mathrm{n}_{4}=1.62, \mathrm{n}_{5}=1.68$ değerleri için yani farklı çekirdek kırılma indisleri için Bağıl kırılma indis farkı $\Delta$ 'nın r yarıçapına göre değișimi çizdirilmiștir.

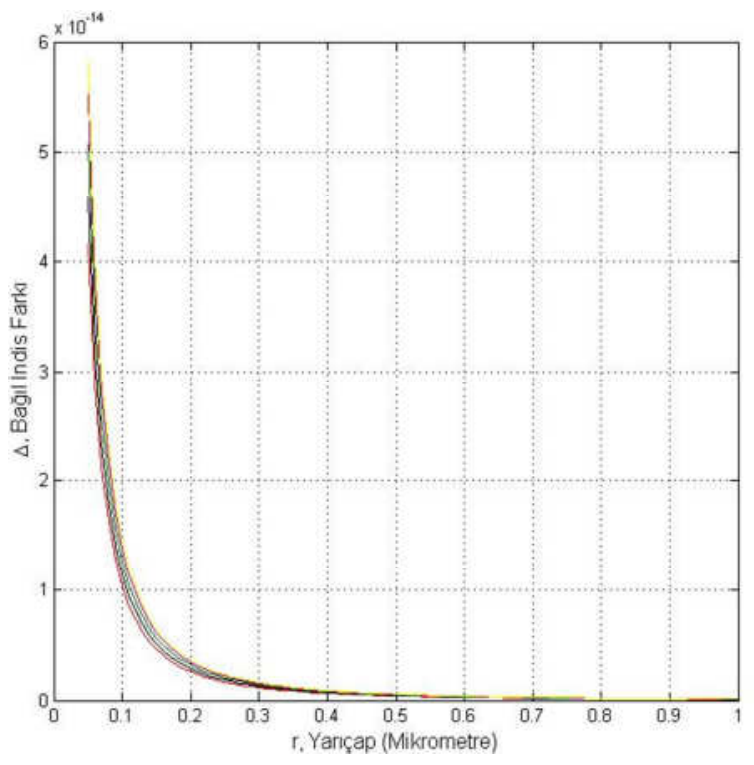

Şekil 9. Bağıl kırılma indis farkı $\Delta$ 'nın farklı kırılma indis değerleri için $r$ yarıçapına göre değişimi.

Her üç şekilde de bağıl kırılma indisi aynı karakterde davranış göstermektedir.

\section{Sonuçlar ve tartışma}

Bu çalıșmada, dalga kılavuzunun içine 1şı̆̆ı alabilme kapasitesini belirleyen sayısal açıklık incelendi. Farklı profil parametreleri için sayısal açıklığın değişik azalmalarla yarıçap arttıkça sıfıra yaklaştığı tespit edildi. Dalga kılavuzu içinde yayılan mod sayısının normalize olmuş frekans (boyutsuz frekans parametresi) değeriyle arttığı görüldü. $\mathrm{V}$ sayısı büyüdüğünde mod sayısının $\mathrm{V}$ değerinin karesiyle orantılı olduğu belirlendi. V değerinin, tek modu besleyen optik fiber tasarımını sağlayacağı söylenebilir. Çekirdek ve örtü kırılma indisleri arasındaki farkı gösteren bağıl kırılma indis farkının fiber yarıçapına göre değişiminin, farklı dalga boyları için, farklı kırılma indisleri için ve farklı boyutsuz frekans parametreleri için aynı karakterde olduğu görüldü. Yarıçap büyüdükçe bağıl indis farkının sıfıra doğru yaklaşmakta ve asimtotik bir davranış gösterdiği tespit edildi.

Yukarıda bahsedilen yapı parametrelerinin optimizasyonları yapılarak optik fiberlerin endüstride, medikal tanı, görüntüleme ve cerrahi işlemlerde, ses ve görüntü sinyallerinin iletimi ile haberleşmedeki kullanım alanları genişletilebilir. 
Kaynaklar

[1] Topdemir, H.G., Işığın Öyküsü: Mitolojiden Matematiğe Işı Kuramlarının Tarihsel Gelişimi, Tübitak Popüler Bilim Kitapları, Ankara, (2000).

[2] Hecht, J., City of Light: The Story of Fiber Optics, Oxford University Press, (2004).

[3] Ghatak, A. ve Thyagarajan, K., An Introduction to Fiber Optics, Cambridge University Press, (1998).

[4] Crisp, J., Introduction to Fiber Optics, Elsevier, (2005).

[5] Senior, J.M. ve Jamro, M.Y., Optical Fiber Communications: Principles and Practice, Pearson Education, (2009).

[6] Pollack, G.L. ve Daniel R.S.,

Electromagnetism, Addison-Wesley, (2002).

[7] Pasachoff, N. (Çeviri Uslu, L.), Alexander Grahambell bağlantı kurmak, Tübitak Popüler Bilim Kitapları, (2000).

[8] Wilson, J. ve Hawkes, J.F.B., Optoelectronics: An Introduction, Prentice Hall, (1988).

[9] Kapany, N.S., Fiber Optics, Academic Press, NewYork-London, (1967).

[10] Kapany, N.S. ve Burke, J.J., Optical Waveguides, Academic Press, NewYorkLondon, (1972).

[11] Aydın, R., Lazer ve Temel Uygulamaları, Odtï Yayıncılık, (2016).

[12] Kao, K.C. ve Hockham, G.A., Dielectric Fibre Surface Waveguides for Optical
Frequencies, Proceedings IEE, 113, 11511158, (1966).

[13] Yan, C., Huang, S.J., Miao, Z., Chang, Z., Zeng, J.Z. ve Wang, T.Y., 3D Refractive Index Measurements of Special Optical Fibers, Optical Fiber Technology, 31, 6573, (2016).

[14] Peng, Y., Jia, H. ve Fang, L., Theoretical Analysis of Hollow Ring-Core Optical Fibre for Transmitting Orbital Angular Momentum Modes, Journal of Modern Optics, 64-18, 1818-1832, (2017).

[15] Wang, H., Chen, M.Y., Wu, X.S., Li, R.H., Cai, Z.M., Li, L.M., Yang, J.H., Zhu, Y.F. ve Fu, P.P., Single-Mode Operation in FewMode Optical Fibre Based on Resonant Coupling, Journal of Modern Optics, 64, 8, 866-870, (2017).

[16] Mishra, A.K., Kumar, M., Kumar, D. ve Singh, O., Modal Study of Plasma Cladded Cylindrical Optical Fiber, Journal of Electromagnetic Waves and Applications, 27, 7, 868-876, (2013).

[17] Çetin, A., Fiber optik dalga kılavuzlarında 1şıyan enerji ölçümü, Doktora Tezi, Eskişehir Osmangazi Üniversitesi, Fen Bilimleri Enstitüsü, Eskişehir, (1998).

[18] Gloge, D., Weakly Guiding Fibers, Applied Optics, 10, 2252-2258, (1971).

[19] Matsumura, H., The Light Accaptance Angle of a Graded Index Fibre, Optical and Quantum Electronics, 7, 81-86, (1975). 


\title{
Optik fiber dalga kılavuzlarının yapı parametrelerinin incelenmesi
}

\author{
Ali ÇETIN ${ }^{1, *}$, Hamza Yaşar OCAK ${ }^{2}$ \\ ${ }^{1}$ Eskişehir Osmangazi Üniversitesi, Fen Edebiyat Fakültesi, Fizik Bölümü, Eskişehir. \\ ${ }^{2}$ Dumlupınar Üniversitesi, Fen Edebiyat Fakültesi, Fizik Bölümü, Kütahya. \\ Gelis Tarihi (Recived Date): 19.08 .2017 \\ Kabul Tarihi (Accepted Date): 23.11 .2017
}

\begin{abstract}
Özet
Optik fiber dalga kılavuzları silindirik geometriye sahip, ışığın içinde yayıldı̆̆ı fotonik devre elemanlarıdır. En genel şekilde iki kısımdan meydana gelir. İç kısmı yüksek kırılma indisli çekirdek olarak adlandırlan kısımdır. Bunu çevreleyen ikinci kısım daha düşük kırllma indisine sahip olup örtü olarak adlandırllır. Optik fiberin özelliği bazı yapı parametreleriyle tanımlanır. Sayısal açıklık, bu dalga kılavuzunun ışıı toplama kapasitesini belirler. Çekirdek ve örtünün kırllma indisleri, ışı̆̆ın dalga kllavuzu içinde ilerleyebilmesi için toplam iç yansımayı sağlar. Normalize olmuş frekans, dalga kılavuzunda yayılan modları belirler. Çekirdek ve örtü kırılma indisleri arasındaki farkı gösteren bağıl kırılma indis farkl, ışığı bu dalga kılavuzunun nasıl kılavuzlandıracă̆ını belirler. Bu çalışmada yukarıda bahsedilen yapı parametreleri arasındaki ilişsiler incelenmişstir.
\end{abstract}

Anahtar kelimeler: Optik fiber, saylsal açıklık, kırılma indisi, dağılım.

\section{Investigation of structural parameters of optical fiber waveguides}

\begin{abstract}
Optical fiber waveguides with cylindrical geometry are photonic circuit elements that light is guided inside. It usually consists of two parts. The inside part which is called as core has high refractive index. The second part that is surrounding the core has lower refractive index and that is called as cladding. The property of optical fiber is defined by some structure parameters. The numerical aperture determines the light-gathering capacity of this waveguide. Refractive indexes of the core and the cladding provide total internal reflection in order to propagating the light inside waveguide. Normalized frequency determines the modes that propagated in waveguide. The relative refractive index difference which indicates the difference between the core refractive index and the cladding refractive index determine how guiding the light in this waveguide. In this study, the relations between the parameters that are given above were investigated.
\end{abstract}

Keywords: Optical fiber, numerical aperture, refractive index, dispersion.

\footnotetext{
*Ali ÇETiN, acetin@ogu.edu.tr, http://orcid.org/0000-0003-0468-8087

Hamza Yaşar OCAK, hyasar.ocak@dpu.edu.tr, http://orcid.org/0000-0003-3094-3459
} 


\section{Giriş}

İletişim, bilginin bir yerden başka bir yere taşınması şeklinde tanımlanabilir. Bilginin ışık ile taşınma düşüncesinin kökeni çok uzun yıllar öncesine dayanmaktadır. İbnü'l Heysem'in çalışmalarında da en çok görme, 1 şı̆̆ın kaynağı, yansıma ve kırılma olayları ele alınmıştır [1]. 1841'de Daniel Colladon ışı̆̆ın su içinde kılavuzlanabileceğini yani yönlendirilebileceğini göstermiştir [2]. Aynı işlemleri 1854'de John Tyndall, Colladon'un yaptığından habersiz olarak gerçekleştirmiştir [3-5]. $\mathrm{Bu}$ çalışmalar karanlık ortamda yapıldığından açık havada su ile hava arasında 1şıma olayı söz konusudur.

Maxwell denklemlerinin 1864 yılında ortaya çıkışından bu yana elektromanyetik dalgaların yayınımı analiz edilmektedir. Maxwell tarafından kurulan matematiksel teoriyle, 1şı̆̆ın elektromanyetik dalga olduğu ortaya çıkmıştır. Bu denklemler elektromanyetik dalga yayınımı ve 1şığın doğasının işleyişi hakkında önemli fikirler vermektedir [6].

1880'de A. G. Bell, fotofon adı verilen aygıtı tasarlayarak ilk kez çalıştırmıştır [7]. Bu aygıtı kullanarak bir 1şın demeti üzerinde ses sinyallerinin iletilebileceğini göstermiştir. Bell tarafından yapılan ışık ile bilgi taşınmasını içeren bu ilk çalışma, açık havada 200 metrelik mesafede güneş ışınını modüle ederek ses iletimini sağlamıştır. Ancak, kapalı havalarda ses sinyallerini iletim verimininin çok düşük oluşu, güneş ışınının boşlukta saçılması, aynı zamanlarda telefonun bulunması, fotofon üzerine yapılan çalışmaların durmasına neden olmuştur.

1910'da Hondros ve Debye 1şı̆̆ın dielektrik ortamda iletimini teorik olarak incelemiştir, ilk örtüsüz cam fiber 1920'de Schriever tarafından elde edilmiştir [5]. 1930 y1lında İngiliz J. L. Baird ile Amerikalı L. W. Hansell kaplamasız fiber kablolar aracılığı ile televizyon görüntülerini tarayarak ve ileterek patent aldılar [8]. Birkaç yıl sonra Alman H. Lamm tek bir cam fiberden görüntüleri başarılı bir şekilde iletti. 1951 yilında A. C. S. Van Heel ile İngiltere'den H. H. Hopkins ve N. S. Kapany fiber demetleri aracılığıyla ışık iletimi üzerine deneyler yaptılar. $\mathrm{Bu}$ bilim adamlarının araştırmaları, tıp alanında tanı ve tedavide geniş bir kullanıma sahip olan esnek fiberskopun geliştirilmesine olanak sağladı [9]. N. S. Kapany, "Optik Fiber" kavramını literatüre kazandırmıştır [10].

Kullanılan 1şık kaynaklarından gelen 1şı̆̆ın dağılması ve 1şı̆̆ı yönlendirecek ortamın uygun olmaması bu konu üzerine çalışmalarda en önemli iki sorun olarak görülmekteydi.
Theodore Maimann 1960 yılının Mayıs ayında ilk katı hal laserini (Yakut laseri) çalıştırmayı başardı. Aynı yıl Aralık ayında Ali Javan ilk kez HeliumNeon laserini keşfetti [11].

Laserin bulunması optik fiber ile ilgili çalışmaları hızlandırdı. Laser yüksek frekansta ayarlanabilme, yönlülük, tek dalga boylu olması, düşük demet ıraksaması gibi önemli özellikleriyle optik iletişim için iyi bir $1 s ̧ ı k$ kaynağı olmuştur. Işık kaynağ1 sorunu çözüldüğü için çalışmalar 1 şı̆̆ 1 içinde yönlendirecek uygun ortam üzerine yoğunlaşmıştır.

1966'da C. K. Kao, G. A. Hockham ve A. Werts tarafından ilk kez örtülü cam fiberin kullanılabileceği önerilmiştir [12]. Başlangıçta fiber optik iletişism sistemleri $1000 \mathrm{~dB} / \mathrm{km}$ 'lik büyük bir zayıflamaya sahipti. On yıl içinde zayıflamanın 5 $\mathrm{dB} / \mathrm{km}$ 'ye düşürülmesi, bunları diğer iletişim sistemleriyle kıyaslanabilir duruma getirmiştir. Zayıflamanın $0.2 \mathrm{~dB} / \mathrm{km}$ 'ye kadar düşürülmesiyle kuramsal alt sınıra ulaşılmıştır.

Bugüne kadar süregelen üretim teknolojisindeki hızlı gelişmelerle fiber optik kablolar seri olarak üretilebilmekte ve bunları içeren iletişim sistemleri diğer iletişim sistemlerinden daha fazla tercih edilmektedir.

Günümüzde hemen hemen her gün yeni bir kullanma alanı ortaya çıkmakta, birçok araştırmacı optik fiberlerin temel karakteristikleri üzerine çalışmalarını sürdürmektedir [13-16].

Optik fiberin kalitesini yapı parametreleri belirler. $\mathrm{Bu}$ çalışmada, yapı parametrelerinin hangi niceliklere göre değiştiği, nasıl etkilendiği ve birbirleri arasındaki ilişkiler nümerik olarak incelenmiştir. Böylece, optik fiberin yap1 parametreleri optimize edilerek bu tümleşik optik devre elemanlarının daha verimli kullanılması sağlanabilir.

\section{Teori}

Optik fiberler silindirik geometriye sahiptir. Geometrik yapısı Şekil 1'de görülen optik fiberde genel olarak kırılma indisi $\mathrm{n}_{1}$ olan bir madde, kırılma indisi kendisinden daha küçük $\mathrm{n}_{2}$ olan başka bir madde ile çevrelenmiştir.

Optik fiberlerin amacı içinde 1şık taşımak olduğu için tam iç yansıma olayının sağlanması gerekir. Bu yüzden iç kısımdaki maddenin kırılma indisi dış kısımdaki maddenin kırılma indisinden daha büyük olmalıdir. 


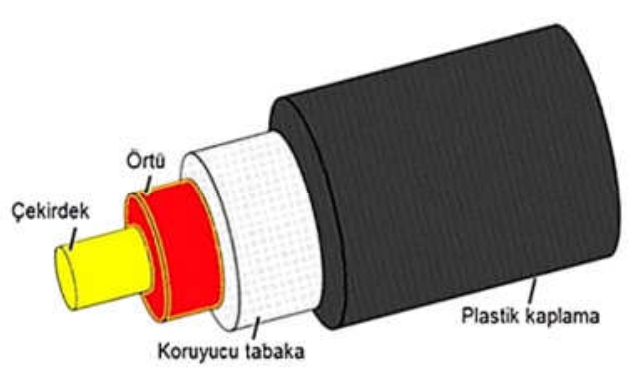

Şekil 1. Optik fiberin geometrik yapısı.

Optik fiberler, kırılma indis profillerine göre basamak indisli ve değişen indisli optik fiber kablolar olmak üzere iki gruba ayrılır. Optik fiber içindeki kırılma indisi bağıntısı

$$
\mathrm{n}(\mathrm{r})=\left\{\begin{array}{c}
\mathrm{n}_{1}\left[1-2 \Delta\left(\frac{\mathrm{r}}{\mathrm{a}}\right)^{\mathrm{g}}\right]^{1 / 2} ; \mathrm{r}<\mathrm{a}(\text { çekirdek) } \\
\mathrm{n}_{2}(1-2 \Delta)^{1 / 2} ; \mathrm{r} \geq \mathrm{a} \text { (örtui) }
\end{array}\right.
$$

ile verilmektedir. Bağıntıdaki a, çekirdek kısmının yarıçapını; $\Delta$ bağıl kırılma indis farkını; g profil parametresini gösterir. $\mathrm{g}$ sonsuz ise optik fiber basamak indisli; g, 1'den başlayarak değer alırsa optik fiber kablo değişen indisli olarak adlandırılır.

Bir ortamdaki elektrik ve manyetik alanların davranışı hakkındaki fiziksel temel, Maxwell denklemleri ile sağlanır. Elektrik alan, manyetik alan, elektrik akı yoğunluğu ve manyetik akı yoğunluğu birbirleriyle

$\mathbf{D}=\varepsilon \mathbf{E}$

ve

$\mathbf{B}=\mu \mathbf{H}$

bağıntılarıyla ilişkilidir. Burada $\varepsilon$ permitivitesi ve $\mu$ permeabilitesi

$\varepsilon=\varepsilon_{0} \varepsilon_{\mathrm{r}}$

ve

$\mu=\mu_{0} \mu_{\mathrm{r}}$

şeklinde tanımlanır. Denklemlerdeki $\varepsilon_{0}$ ve $\mu_{0}$ boşluğun permitivitesi ile permeabilitesi, $\varepsilon_{\mathrm{r}}$ ve $\mu_{\mathrm{r}}$ ise maddenin bağıl permitivitesi ve bağıl permeabilitesidir. Manyetik olmayan maddeler için $\mu_{\mathrm{r}}=1$ alınır. Serbest yüklerin olmadığı $(\rho=0)$, manyetik olmayan maddeler için Maxwell denklemleri aşağıdaki gibidir:

$\nabla \mathbf{X E}=-\frac{\partial \mathbf{B}}{\partial \mathrm{t}}$

$$
\begin{aligned}
& \nabla \mathbf{X H}=\frac{\partial \mathbf{D}}{\partial \mathrm{t}} \\
& \nabla \cdot \mathbf{D}=0 \\
& \nabla \cdot \mathbf{B}=0
\end{aligned}
$$

\section{Modelleme ve simülasyonlar}

Optik fiber, silindirik geometriye sahip olduğundan Şekil 2'deki gibi silindirik koordinatlarda tanımlanabilir.

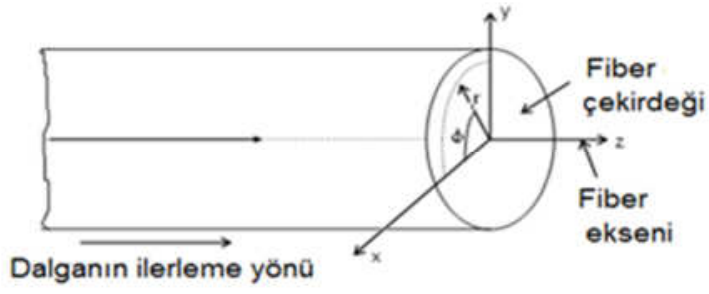

Şekil 2. Optik fiberin silindirik koordinatlarda tanımlanması.

Optik fiber silindirik geometriye sahip olduğundan bunun içindeki elektromanyetik dalganın hareketi Maxwell denklemlerinden yola çıkılarak silindirik koordinatlarda aşağıdaki gibi bulunur [17]:

$$
\begin{aligned}
& \frac{\partial^{2} \mathrm{E}_{\mathrm{z}}}{\partial \mathrm{r}^{2}}+\frac{1}{\mathrm{r}} \frac{\partial \mathrm{E}_{\mathrm{z}}}{\partial \mathrm{r}}+\frac{1}{\mathrm{r}^{2}} \frac{\partial^{2} \mathrm{E}_{\mathrm{z}}}{\partial \phi^{2}}+\mathrm{q}^{2} \mathrm{E}_{\mathrm{z}}=0 \\
& \frac{\partial^{2} \mathrm{H}_{\mathrm{z}}}{\partial \mathrm{r}^{2}}+\frac{1}{\mathrm{r}} \frac{\partial \mathrm{H}_{\mathrm{z}}}{\partial \mathrm{r}}+\frac{1}{\mathrm{r}^{2}} \frac{\partial^{2} \mathrm{H}_{\mathrm{z}}}{\partial \phi^{2}}+\mathrm{q}^{2} \mathrm{H}_{\mathrm{z}}=0
\end{aligned}
$$

Silindirik koordinatlardaki parametreler $(\mathrm{r}, \phi, \mathrm{z})$ olarak verilir. Eșitlik (10) ve (11) sirasıyla elektrik ve manyetik alanların boyuna bileşenlerinin enine değişkenler cinsinden değişimlerini ifade etmektedir.

Bu iki denklem aşağıdaki koșullar altında çözülebilir:

a) $r=0$ için elektromanyetik alan sonlu olmalıdır.

b) $\mathrm{r} \rightarrow \infty$ için $\mathrm{E}_{\mathrm{z}}=0$ ve $\mathrm{H}_{\mathrm{z}}=0$ olmalıdır.

c) $\mathrm{E}_{\mathrm{z}}, \mathrm{H}_{\mathrm{z}}, \mathrm{E}_{\mathrm{r}}, \mathrm{H}_{\mathrm{r}}, \mathrm{E}_{\mathrm{f}}, \mathrm{H}_{\mathrm{f}}$ sınırda sürekli olmalıdır.

i çekirdek ve örtü bölgelerini temsil eden indis olmak üzere

$\mathrm{q}_{\mathrm{i}}^{2}=\omega^{2} \varepsilon_{\mathrm{i}} \mu_{\mathrm{o}}-\beta_{\mathrm{i}}^{2} ; \quad \mathrm{i}=1,2$

alınır.

z'ye dik düzlemdeki değişim için

$\nabla_{\mathrm{t}}^{2}=\nabla^{2}-\frac{\partial^{2}}{\partial \mathrm{z}^{2}}$

eşitliği kullanılarak 


$$
\left(\nabla_{\mathrm{t}}^{2}+\mathrm{q}_{\mathrm{i}}^{2}\right)\left\{\begin{array}{c}
\mathrm{E}_{\mathrm{zi}}(\mathrm{r}, \phi) \\
\mathrm{H}_{\mathrm{zi}}(\mathrm{r}, \phi)
\end{array}\right\}=0 ; \quad \mathrm{i}=1,2
$$

şeklinde iki denklem yazılabilir.

z’ye dik düzlemdeki değişim için silindirik koordinatlardaki dalga denklemini gösteren eşitlikler

$\mathrm{E}_{\mathrm{z}}(\phi, \mathrm{r})=\mathrm{F}(\phi) \mathrm{F}(\mathrm{r})$

$\mathrm{H}_{\mathrm{z}}(\phi, r)=\mathrm{F}(\phi) \mathrm{F}(\mathrm{r})$

şeklinde yazılabilir. Fiber optiğin kesiti dairesel simetrik olduğundan, $v$ pozitif veya negatif bir tamsayı olmak üzere

$\mathrm{F}(\phi)=\mathrm{A} \mathrm{e}^{\mathrm{j} u \phi}$

kabul edilir ve gerekli ara işlemler yapılırsa

$$
\frac{\partial^{2} \mathrm{~F}(\mathrm{r})}{\partial \mathrm{r}^{2}}+\frac{1}{\mathrm{r}} \frac{\partial \mathrm{F}(\mathrm{r})}{\partial \mathrm{r}}+\left(\mathrm{q}^{2}-\frac{v^{2}}{\mathrm{r}^{2}}\right) \mathrm{F}(\mathrm{r})=0
$$

şeklinde Bessel diferansiyel denklemine ulaşılır.

Eş.(1) ile verilen kırılma indisinin yarıçapla değişimi g profil parametresinin sirasiyla 1, 2, 5, 10 ve $\infty$ değerleri için Şekil 3'de çizdirilmiştir.

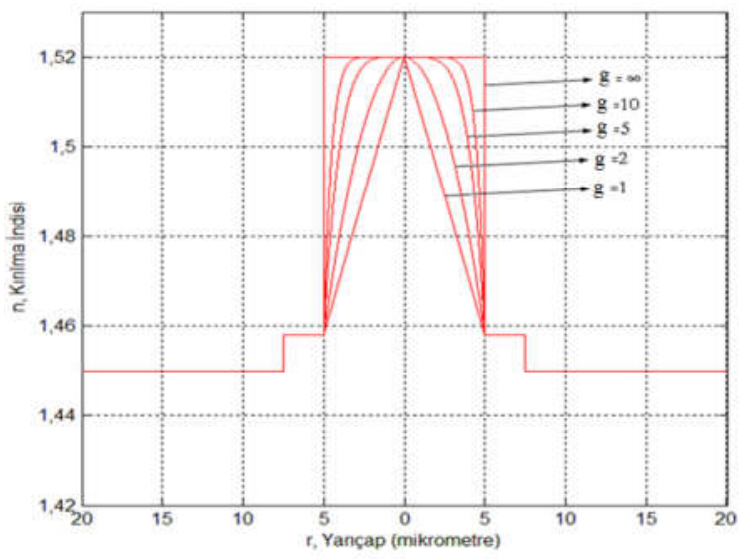

Şekil 3. Optik fiberin kırılma indisinin yarıçapla değişimi.

Şekil 3'den görüldüğü gibi optik fiberin merkezi ekseni üzerinde $r=0$ konumunda çekirdeğin kırılma indisi 1.52 olup çekirdek içinde yarıçap büyüdükçe kırılma indis değeri sabit kalmaktadır. $\mathrm{r}=5 \mu \mathrm{m}$ olunca örtü tabakasına ulaşılıp kırılma indisi 1.4575 oluyorsa optik fiber basamak indisli olarak adlandırılır. $\mathrm{Bu} \quad \mathrm{g}=\infty$ olduğu duruma karşılık gelmektedir. Optik fiberin merkezi ekseni üzerinde $\mathrm{r}=0$ konumunda çekirdeğin kırılma indisi 1.52 olup bu en büyük değerden yarıçap büyüdükçe kırılma indis değeri düşerek $\mathrm{r}=5 \mu \mathrm{m}$ olunca örtü tabakasına ulaşılıp kırılma indisi 1.4575 oluyorsa optik fiber değişen indisli olarak adlandırılır. Bu durumda, $\mathrm{g}=1$ için optik fiber üçgen profile, $\mathrm{g}=2$ için optik fiber kuadratik profile, $\mathrm{g}=\infty$ için optik fiber basamak indis profiline sahiptir.

Eş.(18) ile verilen Bessel diferansiyel denkleminin birbirinden bağımsız iki çözümü vardır. $\mathrm{J}_{v}(\mathrm{ur})$ Bessel fonksiyonu ve $Y_{v}$ (ur) Neumann fonksiyonudur. $\mathrm{r}=0$ 'da elektromanyetik alanın sonlu olması gerektiğinden çekirdek bölgesindeki çözümler, $\mathbf{J}_{v}$ (ur) Bessel fonksiyonları olmalıdır. Koordinat ekseni üzerinde sonsuz değer aldıkları için, $Y_{v}$ (ur) çözümleri kullanılamaz.

Bessel fonksiyonunun kökleri, optik fiber içinde yayılan elektromanyetik modların kesim değerlerini verir. Bu kesim değerlerinden yararlanılarak

$\mathrm{V}=\frac{2 \pi \mathrm{a}}{\lambda}\left(\mathrm{n}_{1}^{2}-\mathrm{n}_{2}^{2}\right)^{1 / 2}$

bağıntısı bulunur. Buna normalize olmuş frekans denir. Bu değer, boyutsuz bir parametre olduğundan optik fiberin $\mathrm{V}$ sayısı ya da $\mathrm{V}$ değeri olarak da adlandırılır. Optik fiber modları, V sayısı sırasıyla, $2.405,3.83,5.14,5.52,6.38,7.02,7.59,8.42 \ldots$ gibi değerler aldığında ortaya çıkar. V sayısı 2.405 değerine ulaşıncaya kadar sadece tek bir mod (EH) mod yayılır. Bu mod, melez enine elekromanyetik moddur. Şekil 4'de optik fiberdeki mod sayısının, V değerine göre değişimi çizilmiştir.

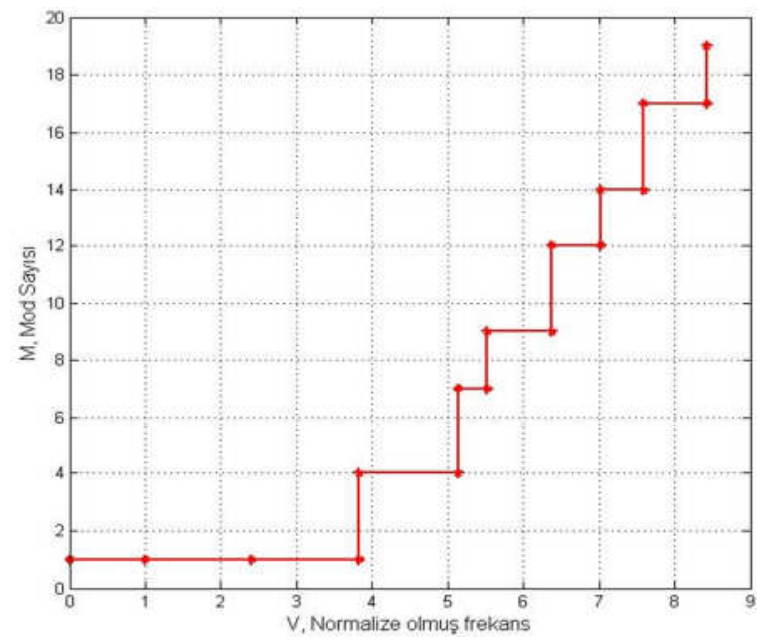

Şekil 4. Mod sayısının, V sayısına karşılık değişimi.

Işığın optik fiber içinde ilerleyebilmesi için, fibere girerken fiber ekseni ile yaptığı en büyük açıya kabul açısı denir ve $\theta_{\text {maks }}$ ile gösterilir. Bu açıya eşit veya daha küçük bir açıda giren 1şık, çekirdek-örtü arayüzeyindeki tam iç yansımalarla, fiber boyunca kılavuzlanır. $\theta_{\text {maks }}$ dan daha büyük açı ile gelen 1 şık ise çekirdek örtü arayüzeyinde tam yansıma koşulunu gerçekleştiremez ve örtü içinde radyasyonla kaybolur. Böylece $\theta_{\text {maks }}$ ile tanımlanan "kabul konisi" içinde kalan 1şın optik fiberin 
çekirdeğinde kalarak kılavuzlanır. Şekil 5'de ilk durumu A 1şını, ikinci durumu ise B 1şını göstermektedir.

Üç ortamın yani çekirdek, örtü ve havanın kırılma indisleri ile kabul açısı arasında bir bağıntı bulmaya çalışalım. Şekil 5'de $\theta_{\text {maks }}$ değerinden daha küçük bir $\theta_{1}$ açısıyla fibere giren 1 şı̆̆ inceleyelim. Snell yasasını D ve E noktalarında kullanarak

$\mathrm{n}_{\mathrm{o}} \sin \theta_{1}=\mathrm{n}_{1} \sin \theta_{2}$

ve

$\mathrm{n}_{1} \sin \phi_{1}=\mathrm{n}_{2} \sin \phi_{2}$

yazabiliriz. DEF üçgenine göre

$\phi_{1}=\frac{\pi}{2}-\theta_{2}$

dir.

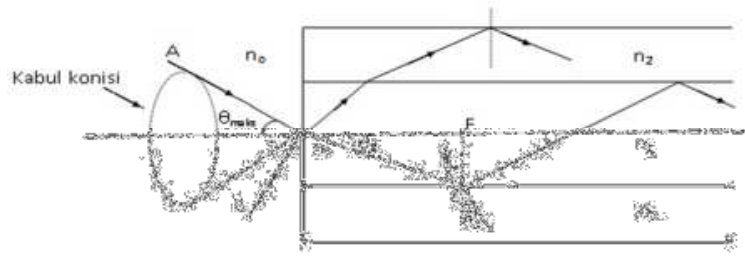

Şekil 5. Bir optik fiberde kabul konisi.

$\theta_{1}$ değeri için üst sınır $\theta_{\text {maks }}$ alınır. E noktasında toplam iç yansımanın sağlanabilmesi için $\phi_{2}$ açısı $\pi / 2$ değerine eşit olmalıdır. Bu sınır değerleri kabul edildiğinde Eş.(20), (21), (22) den yararlanılarak ve $\sin ^{2} \phi_{1}+\cos ^{2} \phi_{1}=1$ trigonometrik özdeşliği kullanılarak

$\mathrm{n}_{\mathrm{o}} \sin \theta_{\text {maks }}=\left(\mathrm{n}_{1}^{2}-\mathrm{n}_{2}^{2}\right)^{1 / 2}$

elde edilir. Boşluğun kırılma indisi $\mathrm{n}_{\mathrm{o}}=1$ kabul edilerek buna 1şığın optik fibere girebileceği maksimum kabul açısı ya da "Sayısal Açıklık" (Numerical Aperture) denilir ve

$\mathrm{NA}=\mathrm{n}_{\mathrm{o}} \sin \theta_{\text {maks }}=\left(\mathrm{n}_{1}^{2}-\mathrm{n}_{2}^{2}\right)^{1 / 2}$

olarak ifade edilir.

Genelde kırılma indislerinin yerine

$\Delta=\frac{\mathrm{n}_{1}^{2}-\mathrm{n}_{2}^{2}}{2 \mathrm{n}_{1}^{2}} \cong \frac{\mathrm{n}_{1}-\mathrm{n}_{2}}{\mathrm{n}_{1}} ; \quad\left(\mathrm{n}_{1} \cong \mathrm{n}_{2}\right)$ şeklinde ifade edilen "bağıl kırılma indis farkı" kullanılır. $\mathrm{Bu}$, optik fiberin önemli yap1 parametrelerinden birisidir. Bağıl kırılma indis fark1 $\Delta$ değeri çok küçük ise optik fibere zayıf kılavuzlayıcı fiber adı verilir [18].

Sayısal açıklık da bağıl kırılma indis farkı cinsinden

$\mathrm{NA} \cong \mathrm{n}_{1}(2 \Delta)^{1 / 2}$

bağıntısıyla ifade edilebilir. Sayısal açıklık, fiberin 1Şı toplayabilme yeteneğinin bir ölçüsüdür. Zayıf kılavuzlayıcı optik fiberde, kırılma indis farkı küçük olacağından sayısal açıklıkta küçük olacaktır. Eş.(24)'e göre sayısal açıklık, optik fibere giren 1şığın fiber ekseni ile yaptığı en büyük açıyı verir [19]. Optik fiberin eksenine göre simetrisinden dolayı $\theta_{\text {maks }}$ açısı fiberin ekseni etrafında bir koni tanımlar. Bu koniye, kabul konisi adı verilir.

Şekil 6'da $\mathrm{n}_{1}=1.52, \mathrm{n}_{2}=1.4575$ olan bir optik fiberde $\mathrm{g}$ profil parametresinin sirasiyla $1,2,5,10$ ve $\infty$ değerleri için sayısal açıklığın yarıçapla değişimi çizdirilmiştir.

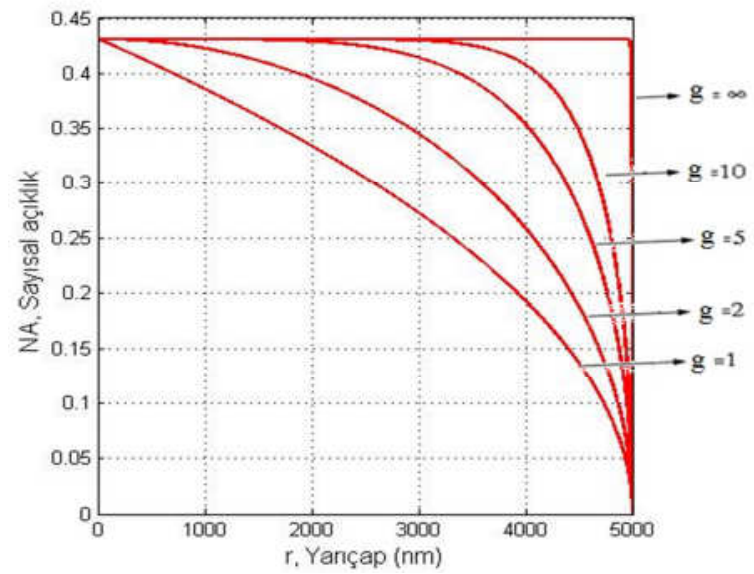

Şekil 6. Bazı g değerleri için sayısal açıklığın yarıçapla değişimi.

Eş.(24)'den görüldüğü gibi sayısal açıklık boyutsuz bir parametre olup sadece optik fiberin çekirdek ve örtü kısımlarının kırılma indisleri $n_{1}$ ve $n_{2}$ değerlerine bağlıdır. Sayısal açıklık değeri Şekil 6'dan görüldüğü gibi optik fiberin ekseni üzerinde çekirdeğin en büyük kırılma indis değeri 1.52 için 0.4313 iken fiber ekseninden dışarıya doğru yarıçap doğrultusunda gidilirse tüm profil parametreleri için sıfır değerine düşmektedir.

Așağıdaki şekillerde Bağıl kırılma indis farkı $\Delta$ 'nın r yarıçapına göre değişimi farklı parametreler için verilmektedir. Şekil 7'de tek mod durumunda yani frekans parametresi $\mathrm{V}=2.405$ alınmıştır. Dalga boyunun $\lambda=632,8 \mathrm{~nm}, \lambda=694 \mathrm{~nm} \lambda=810 \mathrm{~nm}$, $\lambda=1310 \mathrm{~nm}$ ve $\lambda=1550 \mathrm{~nm}$ değerleri için Bağıl 
kırılma indis farkı $\Delta$ 'nın r yarıçapına göre değişimi çizdirilmiştir.

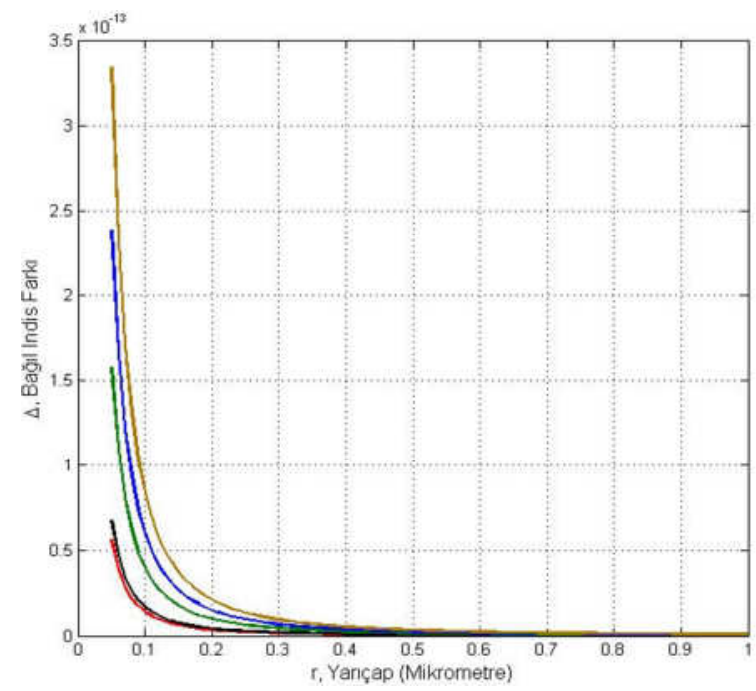

Şekil 7. Bağıl kırılma indis farkı $\Delta$ 'nın farklı dalga boyları için $r$ yarıçapına göre değişimi.

Şekil 8'de tek dalga boyu durumu ele alınmıştır. Dalga boyunun $\lambda=632,8 \mathrm{~nm}$ olduğu durumda $\mathrm{V}=2.405, \mathrm{~V}=2.831, \mathrm{~V}=5.135, \mathrm{~V}=6,380, \mathrm{~V}=7.588$ değerleri için Bağıl kırılma indis farkı $\Delta$ 'nın $\mathrm{r}$ yarıçapına göre değişimi çizdirilmiştir.

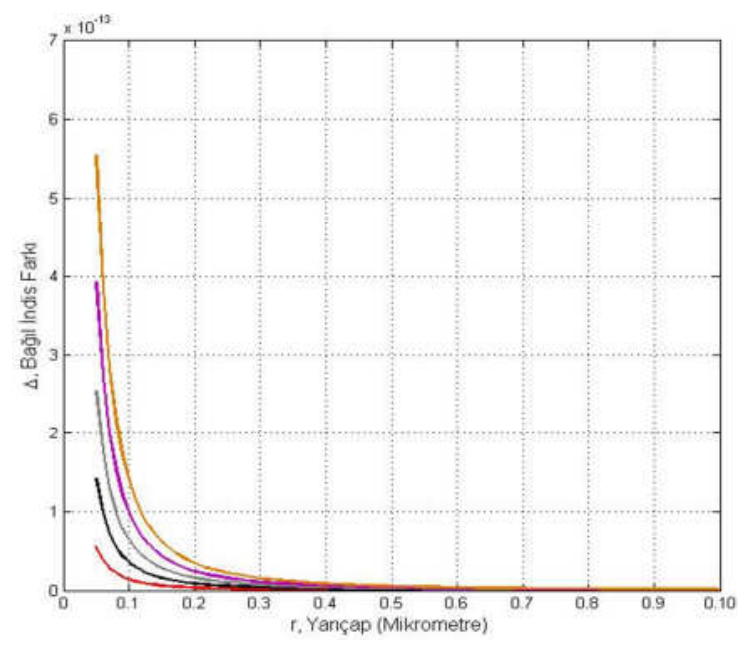

Şekil 8. Bağıl kırılma indis farkı $\Delta$ 'nın farklı V değerleri için $r$ yarıçapına göre değişimi.

Şekil 9'da tek mod durumu ele alınmıştır. Yani $\mathrm{V}=2.405$ alınmıștır. Dalga boyunun $\lambda=632,8 \mathrm{~nm}$ olduğu durumda $\mathrm{n}_{1}=1.42, \quad \mathrm{n}_{2}=1.458, \quad \mathrm{n}_{3}=1.52$, $\mathrm{n}_{4}=1.62, \mathrm{n}_{5}=1.68$ değerleri için yani farklı çekirdek kırılma indisleri için Bağıl kırılma indis farkı $\Delta$ 'nın r yarıçapına göre değișimi çizdirilmiștir.

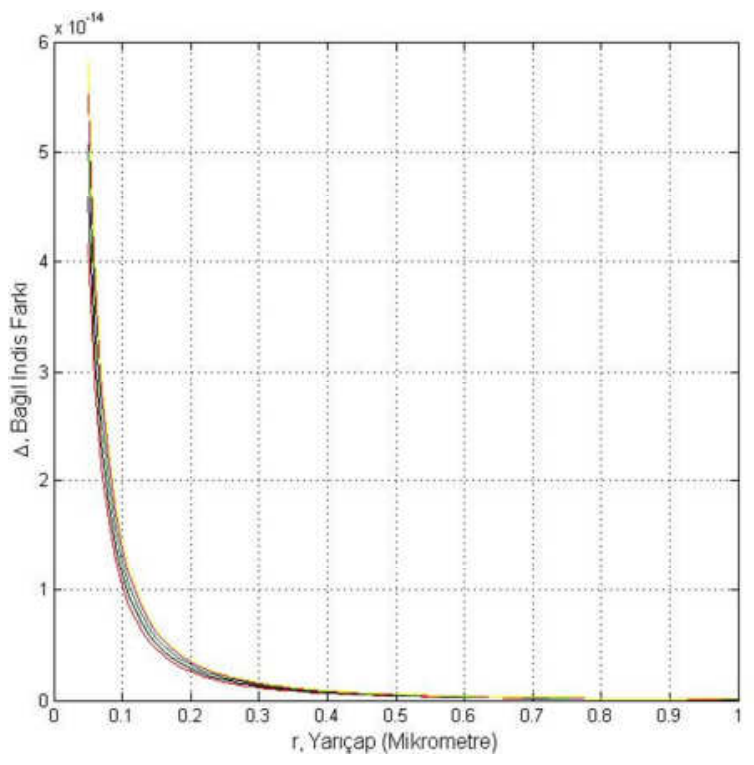

Şekil 9. Bağıl kırılma indis farkı $\Delta$ 'nın farklı kırılma indis değerleri için $r$ yarıçapına göre değişimi.

Her üç şekilde de bağıl kırılma indisi aynı karakterde davranış göstermektedir.

\section{Sonuçlar ve tartışma}

Bu çalıșmada, dalga kılavuzunun içine 1şı̆̆ı alabilme kapasitesini belirleyen sayısal açıklık incelendi. Farklı profil parametreleri için sayısal açıklığın değişik azalmalarla yarıçap arttıkça sıfıra yaklaştığı tespit edildi. Dalga kılavuzu içinde yayılan mod sayısının normalize olmuş frekans (boyutsuz frekans parametresi) değeriyle arttığı görüldü. $\mathrm{V}$ sayısı büyüdüğünde mod sayısının $\mathrm{V}$ değerinin karesiyle orantılı olduğu belirlendi. V değerinin, tek modu besleyen optik fiber tasarımını sağlayacağı söylenebilir. Çekirdek ve örtü kırılma indisleri arasındaki farkı gösteren bağıl kırılma indis farkının fiber yarıçapına göre değişiminin, farklı dalga boyları için, farklı kırılma indisleri için ve farklı boyutsuz frekans parametreleri için aynı karakterde olduğu görüldü. Yarıçap büyüdükçe bağıl indis farkının sıfıra doğru yaklaşmakta ve asimtotik bir davranış gösterdiği tespit edildi.

Yukarıda bahsedilen yapı parametrelerinin optimizasyonları yapılarak optik fiberlerin endüstride, medikal tanı, görüntüleme ve cerrahi işlemlerde, ses ve görüntü sinyallerinin iletimi ile haberleşmedeki kullanım alanları genişletilebilir. 
Kaynaklar

[1] Topdemir, H.G., Işığın Öyküsü: Mitolojiden Matematiğe Işı Kuramlarının Tarihsel Gelişimi, Tübitak Popüler Bilim Kitapları, Ankara, (2000).

[2] Hecht, J., City of Light: The Story of Fiber Optics, Oxford University Press, (2004).

[3] Ghatak, A. ve Thyagarajan, K., An Introduction to Fiber Optics, Cambridge University Press, (1998).

[4] Crisp, J., Introduction to Fiber Optics, Elsevier, (2005).

[5] Senior, J.M. ve Jamro, M.Y., Optical Fiber Communications: Principles and Practice, Pearson Education, (2009).

[6] Pollack, G.L. ve Daniel R.S.,

Electromagnetism, Addison-Wesley, (2002).

[7] Pasachoff, N. (Çeviri Uslu, L.), Alexander Grahambell bağlantı kurmak, Tübitak Popüler Bilim Kitapları, (2000).

[8] Wilson, J. ve Hawkes, J.F.B., Optoelectronics: An Introduction, Prentice Hall, (1988).

[9] Kapany, N.S., Fiber Optics, Academic Press, NewYork-London, (1967).

[10] Kapany, N.S. ve Burke, J.J., Optical Waveguides, Academic Press, NewYorkLondon, (1972).

[11] Aydın, R., Lazer ve Temel Uygulamaları, Odtï Yayıncılık, (2016).

[12] Kao, K.C. ve Hockham, G.A., Dielectric Fibre Surface Waveguides for Optical
Frequencies, Proceedings IEE, 113, 11511158, (1966).

[13] Yan, C., Huang, S.J., Miao, Z., Chang, Z., Zeng, J.Z. ve Wang, T.Y., 3D Refractive Index Measurements of Special Optical Fibers, Optical Fiber Technology, 31, 6573, (2016).

[14] Peng, Y., Jia, H. ve Fang, L., Theoretical Analysis of Hollow Ring-Core Optical Fibre for Transmitting Orbital Angular Momentum Modes, Journal of Modern Optics, 64-18, 1818-1832, (2017).

[15] Wang, H., Chen, M.Y., Wu, X.S., Li, R.H., Cai, Z.M., Li, L.M., Yang, J.H., Zhu, Y.F. ve Fu, P.P., Single-Mode Operation in FewMode Optical Fibre Based on Resonant Coupling, Journal of Modern Optics, 64, 8, 866-870, (2017).

[16] Mishra, A.K., Kumar, M., Kumar, D. ve Singh, O., Modal Study of Plasma Cladded Cylindrical Optical Fiber, Journal of Electromagnetic Waves and Applications, 27, 7, 868-876, (2013).

[17] Çetin, A., Fiber optik dalga kılavuzlarında 1şıyan enerji ölçümü, Doktora Tezi, Eskişehir Osmangazi Üniversitesi, Fen Bilimleri Enstitüsü, Eskişehir, (1998).

[18] Gloge, D., Weakly Guiding Fibers, Applied Optics, 10, 2252-2258, (1971).

[19] Matsumura, H., The Light Accaptance Angle of a Graded Index Fibre, Optical and Quantum Electronics, 7, 81-86, (1975). 